\title{
Influence of acute mental stress on blood pressure, heart rate and heart rate variability in male medical students: An experimental study from tertiary care hospital, Nepal
}

\author{
Pandey KR ${ }^{1 *}$, Khadka R², Panday $\mathrm{DR}^{3}$, Agrawal K${ }^{4}$, Paudel BH ${ }^{5}$
}

*Corresponding author:

Dr. Karishma Rajbhandari Pandey, Associate Professor, Department of Basic and Clinical Physiology, BPKIHS, Dharan, Nepal.

Email: karishma@bpkihs.edu ORCID

\section{Information about the article:}

Received: Feb 19, 2020

Accepted: May. 3, 2020

Published online: June 30, 2020

Cite this article:

Pandey KR, Khadka R, Panday DR, Agrawal K, Paudel BH. Influence of acute mental stress on blood pressure, heart rate and heart rate variability in male medical students: An experimental study from tertiary care hospital, Nepal. Journal of Biomedical Sciences. 2020; 7(1):11-17

\section{Publisher}

Nepal Health Research Society, Bahundhara -6, Gokarnesowor Municipality, Kathmandu, Nepal eISSN 2382-5545, ISSN 2676-1343 (Print)

(c) The Author(s). 2020

Content licensing: CC BY 4.0

\section{ABSTRACT}

\section{Background}

Medical students experience immense mental stress while understanding and retaining new terms, drug names and mechanisms and eventually generating a concept. Such stress, in long run, may affect their cardiovascular health. This can be assessed by heart rate variability, a reliable nonpenetrating tool to determine the cardiac autonomic tone.

\section{Material and methods}

Thirty healthy young male medical students of BPKIHS, Nepal of age $21.03 \pm 1.73$ years, and BMI $20.83 \pm 2.07$ $\mathrm{kg} / \mathrm{m}^{2}$ were recruited for the present study. Their resting BP, $\mathrm{HR}, \mathrm{RR}$, and short-term heart rate variability (HRV) were recorded in sitting position. Each subject was given a mental stress for $5 \mathrm{~min}$. Their BP, HR, and RR were recorded at 5 th min of mental stress. HRV of $5 \mathrm{~min}$ was also recorded simultaneously during mental stress.

\section{Results}

Mental stress increased SBP ( $\mathrm{p}=0.001), \mathrm{DBP}(\mathrm{p}=0.001), \mathrm{PR}$ $(p=0.005)$ and $R R(p=0.042)$ in young male medical students. Time domain measures of HRV viz; RMSSD ( $\mathrm{p}=$ $0.001)$, NN50 $(\mathrm{p}=0.001)$ and PNN50 $(\mathrm{p}=0.001)$, which are markers of parasympathetic activity, were significantly decreased during mental stress.

\section{Conclusion}

Acute mental stress increases BP and HR by withdrawing parasympathetic nervous control in young, healthy male medical students.

\section{Keywords}

Blood pressure, cardiovascular, heart rate variability, mental stress 


\section{Background}

Stress is imposed on any subject when he/ she is required to actively cope (do something) or perform a challenging situation [1]. Medical education is one such field where the medical students are continuously exposed to stressful situations such as learning and memorizing the concepts and applying the gained knowledge in human subjects [2]. Hence medical students are continuously exposed to mental stress.

This mental stress triggers the sympathetic-adrenalmedullary axis leading it to discharge catecholamine, which consecutively elevates blood pressure (BP) and heart rate (HR) $[3,4]$. It also releases cortisol from the hypothalamopituitary-adrenal axis [5,6], which has a permissive action on the catecholamine for vascular reactivity. Additionally, it has also been proposed that the increase in BP and HR responses are by virtue of diminution in vagal tone $[7,8]$, or an increment in the stimulation of afferent sympathetic nervous system [9, 10]. Regardless of the underlying mechanisms, researches have deduced that enhanced reactivity or slowed down recovery are the ways through which stress and other psychosocial factors help to develop cardiovascular disease risk $[11,12]$.

Also, when one is exposed to such stress for an extended period, it is linked with the progression of atherosclerosis, inflammatory reactivity, endothelial dysfunction, and oxidative stress, which are weighed as primary factors to the development of eventual cardiovascular diseases.

Heart rate variability (HRV) has been used as a tool to assess the influence of acute mental stress on cardiac autonomic activity [1]. It is a non-penetrating device that monitors and measures any alterations or changes in $\mathrm{HR}$ as well as fluctuations of the $\mathrm{R}-\mathrm{R}(\mathrm{N}-\mathrm{N})$ interval. Among many ways of analyzing HRV, the most popular and easy measures is the standard deviation of the mean $\mathrm{R}-\mathrm{R}$ interval (SDRR/ SDNN) [13]. Researches have demonstrated that healthy subjects respond to acute mental stress by an increase in HR while there is a decrease in SDNN [14, 15]. The fluctuations in this instantaneous heartbeat in an irregular style have been postulated to result from numerous influences such as autonomic discharge (PNS \& SNS), hormones, neurochemical substances, end diastolic volume, and afterload [16]. Additionally, it has also been put forwarded that even under regular states, the HR generating system tends to vary between a set of metastable positions $[17,18]$. This functional diversity of sinus node (SA node) not only makes heart capable of shifting from one state to another but also helps to meet all the known and unknown challenges [19]. In this perspective, the regularity of HR rhythm and decreased responsiveness of SA node to varying situations is related to heightened liability of forthcoming cardiovascular diseases [20].

HRV studies have been done utilizing different cognitive challenges such as mental arithmetic, digits repeated backward, delayed auditory feedback task, reaction time test, speech stress, computer quiz and so on [1]. Whereas, standard laboratory stressors have not been explored for the problem-solving ability, which is actually the stressors to CVS and other responses in the body. Thus, in our study, we have used a few selected workout MENSA [21], problem-solving questions as stress, and we are exploring its effect on the cardiovascular autonomic function of young, healthy male medical students. It has been found that increased reactivity to mental stress or delayed recovery from it foresees poor impending cardiovascular disease progression. Thus, this study may also help in identifying this group of students as well.

\section{Material and methods}

\section{Study design and the participants}

An experimental cross-sectional study was done in 30 young, healthy male medical students of B. P. Koirala Institute of Health Sciences (BPKIHS), Dharan.

\section{Mental stress design and its validity}

In this study, the acute mental stress was in the form of nine problem-solving questions from the MENSA workout questionnaire. It was determined after conducting a pilot study on 10 apparently healthy young male medical students. The mental stresses included were 1) reverse counting from 100, 2) subtracting 7 from 1000, and 3) computer-based MENSA workout questionnaire. Among them, the first two stressors did not produce expected cardiovascular effects, and also the tasks were completed before the timeframe of $5 \mathrm{~min}$. Whereas, the nine questions selected on a random basis from MENSA workout questionnaire containing 30 questions effectively produced the desired cardiovascular response, and it took $5 \mathrm{~min}$ to complete the task. In this way, the MENSA workout questionnaire was selected as mental stress in our study.

\section{Data collection}

The subjects who volunteered for the study were asked to come to the neurocardiology laboratory, Department of Basic and Clinical Physiology, BPKIHS, at 10 am- 12 noon. They were instructed to have a light breakfast 2 hours before the recording. On arrival, they were allowed to rest for $15 \mathrm{~min}$, and then their resting $\mathrm{BP}, \mathrm{HR}$, and respiratory rate (RR) were recorded in sitting position. Their resting short term HRV for 5 min was also recorded using polar S810i HRM (Heart rate monitor). For this, a strap with electrodes fitted on either side was used. It was applied around the chest after wetting the electrodes with water. The telemetric signals of ECG were received using a Polar watch placed within $1 \mathrm{~m}$ distance. Subjects were then exposed to acute mental stress. BP was recorded at 4th minute of mental stress, whereas $\mathrm{HR}$ and RR were recorded in the 5 th min. Short term HRV was continuously recorded during the stress period. Rest of 5 min was allowed for recovery. Again BPs, HR, RR, and HRV were recorded as explained earlier during recovery. The R-R interval calculated by the polar watch was then transmitted to a 
computer installed with Polar Precision Performance software via infra-red. HRV software (Kubios HRV version 2.1 released in July 2012, Kuopio, FINLAND) was used to analyze the data.

In order to maintain confidentiality, a serial number was allotted for each data entered.

\section{Inclusion criteria}

Subjects enrolled were healthy young male medical students' of age $21.03+1.73$ years and BMI of $20.83 \mathrm{~kg} / \mathrm{m}^{2}$ \pm 2.07 . For this study, the age group included were $18-26$ years who had a BMI $<25 \mathrm{~kg} / \mathrm{m}^{2}$.

\section{Exclusion Criteria}

Subjects with any history of cardiovascular diseases, diabetes, and psychiatric illness or currently under medication for any diseases were excluded from the study.

\section{Sample size calculation}

For this purpose, we considered a mean and standard deviation of the heart rate from a closely related article "Decrease in heart rate variability response to the task is related to anxiety and depressiveness in normal subjects" by Shinba T, Kariya N, Matsui Y, Ozawa N, Matsuda Y and Yamamoto $\mathrm{K}$, published in 2008. In their study, the HR at rest (mean \pm SD): $71.1 \pm 10.5$ b.p.m and HR during the mental task (mean \pm SD): $78.4 \pm 12.4$ b.p.m. These variables were considered for the sample size estimation. The $G^{*}$ Power 3.1.9.7 software was used for it using "means" of two normally distributed variables of effect size 0.631 . A two-sided test with test hypothesis at significance level 0.05 and power 0.91 , the sample size calculated is 30 .

\section{Data management and statistical analysis}

The data collected were entered in Microsoft excel and were statistically analyzed using SPSS version 17 (SPSS INC., Chicago, ILL, USA). Repeated measures of ANOVA followed by Bonferroni test were used to analyze cardiorespiratory measures. Whereas, HRV was analyzed using the Friedman test followed by multiple comparisons. All data were considered statistically significant at $\mathrm{p}<0.05$.

\section{Outcome variable}

i. Cardiovascular variables: resting BP (SBP \& DBP) and HR and BP (SBP \& DBP) and HR in the $4 \mathrm{t}^{\mathrm{h}}$ min of mental stress and recovery

ii. Respiratory rate: during rest, mental stress, and recovery

iii. HRV variables:

During rest, mental stress, and recovery

a. Time-domain: SDNN, RMSSD, NN50, PNN50

b. Frequency domain: VLF power, HF power, LF power, $\mathrm{HF}(\mathrm{nu}), \mathrm{LF}(\mathrm{nu})$, Total power, LF/HF.

\section{Explanatory variables}

The socio-demographic variables and anthropometric variables.

\section{Ethical committee approval}

The study was carried out after obtaining Ethical approval from the Institutes Review Board, BPKIHS. The Memo number of Ethical Committee Letter issued is Acd.655/069/070. Informed written consent was obtained from all of the enrolled subjects.

\section{Results}

Mental stress significantly increased the cardiorespiratory variables in young male medical students (Table 1 , refer $\mathrm{P}$ value $\mathrm{p} 1)$. The cardiorespiratory variables measured during recovery was comparable to their resting states (Table 1, refer $\mathrm{P}$ value $\mathrm{p} 2$ ).

Table 1: Comparison of cardiorespiratory measures of young male medical students obtained during rest, mental stress and recovery from mental stress

\begin{tabular}{|c|c|c|c|c|c|c|}
\hline \multirow[b]{2}{*}{ Variables } & \multirow[b]{2}{*}{$\begin{array}{c}\text { Rest } \\
\text { Mean } \pm \text { SD }\end{array}$} & \multirow[b]{2}{*}{$\begin{array}{c}\text { Mental stress } \\
\text { Mean } \pm \text { SD }\end{array}$} & \multirow{2}{*}{$\begin{array}{c}\text { Recovery } \\
\text { from mental } \\
\text { stress } \\
\text { Mean } \pm \text { SD }\end{array}$} & \multicolumn{3}{|c|}{$P$ value } \\
\hline & & & & p1 & $\mathrm{p} 2$ & p3 \\
\hline $\begin{array}{l}\text { SBP } \\
(\mathrm{mmHg})\end{array}$ & $112.73 \pm 6.74$ & $121.8 \pm 9.43$ & $111.47 \pm 5.96$ & 0.001 & 0.520 & 0.001 \\
\hline $\begin{array}{l}\mathrm{DBP} \\
(\mathrm{mmHg})\end{array}$ & $76.33 \pm 7.60$ & $86.87 \pm 8.11$ & $75.93 \pm 7.06$ & 0.001 & 1.00 & 0.001 \\
\hline $\begin{array}{l}\text { MAP } \\
(\mathrm{mmHg})\end{array}$ & $100.6 \pm 5.6$ & $110.15 \pm 8.10$ & $90.56 \pm 29.56$ & 0.001 & 0.568 & 0.001 \\
\hline PR (bpm) & $67.20 \pm 9.17$ & $75.30 \pm 11.92$ & $67.80 \pm 9.62$ & 0.002 & 1.00 & 0.006 \\
\hline $\begin{array}{l}\text { RR } \\
\text { (cycles/mi } \\
\text { n) }\end{array}$ & $16.43 \pm 2.90$ & $18.13 \pm 3.24$ & $15.60 \pm 3.28$ & 0.042 & 0.190 & 0.001 \\
\hline
\end{tabular}

$\mathrm{SBP}=$ systolic blood pressure $(\mathrm{mm} \mathrm{Hg}), \mathrm{DBP}=$ diastolic blood pressure $(\mathrm{mm}$ $\mathrm{Hg}), \mathrm{MAP}=$ mean arterial pressure, $\mathrm{PR}=$ pulse rate $(\mathrm{bpm}), \mathrm{RR}=$ respiratory rate (per min), p1= between rest and mental stress (task), p2=between rest and recovery from mental stress, $\mathrm{p} 3=$ between mental stress (task) and recovery from mental stress.

In time domain measures of HRV, there were significant decrease in RMSSD, NN50 and PNN50 during mental stress (Table 2, refer $\mathrm{P}$ value $\mathrm{p} 1$ ). Whereas, these variables during recovery were comparable to resting states (Table 2, refer $\mathrm{P}$ value $\mathrm{p} 2$ ). In frequency domain, there were significant decrease in LF power and HF power during mental stress (Table 2, refer $\mathrm{P}$ value $\mathrm{p} 1$ ). The variables obtained during recovery was comparable to resting states (Table 2, refer P value p2).

\section{Discussion}

\section{Effect of mental stress in BP and HR}

This study assessed the effects of stress on cardiovascular functions using Mensa work-out questionnaire, which had 9 problem solving questions, as mental stress. The stress was given for $5 \mathrm{~min}$. It resulted in a significant increase in SBP, DBP, HR, and RR in young male medical students as compared to both rest and recovery states.

Mental activity is known to increase HR [22, 23]. In a study done by Emilie Pérusse-Lachance et al., [24] mental stress 
in the form of 45-min reading-writing session, elevated $10 \% \mathrm{HR}$.

\begin{tabular}{|c|c|c|c|c|c|c|}
\hline \multicolumn{7}{|c|}{$\begin{array}{l}\text { Table 2: Comparison of HRV measures of young male } \\
\text { medical students obtained during rest, mental stress } \\
\text { and recovery from mental stress }\end{array}$} \\
\hline \multirow[b]{2}{*}{ Variables } & \multicolumn{3}{|c|}{$\begin{array}{l}\text { Male }(n=30) \\
\text { median (interquartile range) }\end{array}$} & \multicolumn{3}{|c|}{$P$ value } \\
\hline & Rest & $\begin{array}{l}\text { Mental } \\
\text { stress } \\
\text { (task) }\end{array}$ & $\begin{array}{l}\text { Recovery } \\
\text { from } \\
\text { mental } \\
\text { Stress }\end{array}$ & p1 & p2 & p3 \\
\hline \multicolumn{7}{|c|}{ Time domain of HRV } \\
\hline $\begin{array}{l}\text { SDNN } \\
(\mathrm{ms})\end{array}$ & $\begin{array}{l}70.9 \\
(58.33- \\
85.85)\end{array}$ & $\begin{array}{l}72.7(60.1 \\
-103.6)\end{array}$ & $\begin{array}{l}72.85 \\
(58.83- \\
85.53)\end{array}$ & 0.267 & 0.355 & 0.558 \\
\hline $\begin{array}{l}\text { RMSSD } \\
(\mathbf{m s})\end{array}$ & $\begin{array}{l}59.8 \\
(52.63- \\
79.88)\end{array}$ & $\begin{array}{l}45.7 \\
(38.13- \\
63.88)\end{array}$ & $\begin{array}{l}59.5(48.55 \\
-78.48)\end{array}$ & 0.001 & 0.565 & 0.001 \\
\hline NN50 & $\begin{array}{l}130(99.5 \\
-182.25)\end{array}$ & $\begin{array}{l}95.5(57- \\
155.5)\end{array}$ & $\begin{array}{l}118.5(91.5 \\
-169)\end{array}$ & 0.001 & 0.229 & 0.008 \\
\hline $\begin{array}{l}\text { pNN50 } \\
(\%)\end{array}$ & $\begin{array}{l}36.6 \\
(26.35- \\
59.1)\end{array}$ & $\begin{array}{l}24.65 \\
(14.5- \\
47.38)\end{array}$ & $\begin{array}{l}36.25 \\
(26.88- \\
56.23)\end{array}$ & 0.001 & 0.313 & 0.001 \\
\hline \multicolumn{7}{|c|}{ Frequency domain measures of HRV } \\
\hline $\begin{array}{l}\text { VLF } \\
\text { power } \\
\left(\mathbf{m s}^{2}\right)\end{array}$ & $\begin{array}{l}1508 \\
(832.75- \\
2617.25)\end{array}$ & $\begin{array}{l}1971 \\
(1012.25- \\
585.5)\end{array}$ & $\begin{array}{l}1758.5 \\
(1006.25- \\
2865.5)\end{array}$ & 0.125 & 0.382 & 0.586 \\
\hline $\begin{array}{l}\text { LF power } \\
\left(\mathbf{m s}^{2}\right)\end{array}$ & $\begin{array}{l}1582 \\
(588.25- \\
2289)\end{array}$ & $\begin{array}{l}990(564- \\
1602.5)\end{array}$ & $\begin{array}{l}1306.5 \\
(815.25- \\
1967.5)\end{array}$ & 0.017 & 0.644 & 0.045 \\
\hline LF (nu) & $\begin{array}{l}51.9 \\
(38.83- \\
59.78)\end{array}$ & $\begin{array}{l}51.6 \\
(38.83- \\
62.63)\end{array}$ & $\begin{array}{l}54.3(43.18 \\
-65.95)\end{array}$ & 0.636 & 0.159 & 0.170 \\
\hline $\begin{array}{l}\text { HF } \\
\text { power } \\
\left(\mathrm{ms}^{2}\right)\end{array}$ & $\begin{array}{l}1460 \\
(1033.25- \\
2091)\end{array}$ & $\begin{array}{l}820 \\
(561.75- \\
1834.75)\end{array}$ & $\begin{array}{l}1190(741- \\
2043.25)\end{array}$ & 0.025 & 0.057 & 0.120 \\
\hline HF (nu) & $\begin{array}{l}48.05 \\
(40.2- \\
61.08)\end{array}$ & $\begin{array}{l}48.3(37.3 \\
-60.85)\end{array}$ & $\begin{array}{l}45.7(33.95 \\
-56.55)\end{array}$ & 0.629 & 0.147 & 0.178 \\
\hline $\mathbf{T P}\left(\mathrm{ms}^{2}\right)$ & $\begin{array}{l}4805 \\
(3167.5- \\
6756.75)\end{array}$ & $\begin{array}{l}4554.5 \\
(2907- \\
7304.25)\end{array}$ & $\begin{array}{l}5111.5 \\
(2761.25- \\
6675)\end{array}$ & 0.658 & 0.766 & 0.926 \\
\hline $\mathbf{L F} / \mathbf{H F}$ & $\begin{array}{l}1.08(0.65 \\
-1.49) \\
\end{array}$ & $\begin{array}{l}1.07(0.64 \\
-1.68) \\
\end{array}$ & $\begin{array}{l}1.19(0.77- \\
1.95)\end{array}$ & 0.530 & 0.139 & 0.106 \\
\hline
\end{tabular}

SDNN = standard deviation of RR interval, RMSSD $=$ root mean square of differences of successive RR intervals, NN50 = number of RR intervals that differ by $\geq 50 \mathrm{~ms}$, pNN50 = percentage of NN50, VLF = very low frequency, $\mathrm{LF}=$ low frequency, $\mathrm{HF}=$ high frequency, power expressed in $\mathrm{ms} 2$ (millisecond), $\mathrm{nu}=$ normalized units, $\mathrm{TP}=$ total power. $\mathrm{p} 1=$ between rest and mental stress (task) p2= between rest and recovery, p3= between mental stress and recovery.

This finding was in line with Martin et al., [23] who reported an increase in $\mathrm{HR}$ by $20 \%(+6.7 \mathrm{bpm})$, and Durocher et al., [25] also noted a similar increase of HR 20 during a single arithmetic task of 5-min duration. Likewise, our study also showed an increase in HR by $13.01 \%$ during mental stress. The reason for this increase was deduced to be due to a reduction in cardiac parasympathetic modulation during mental work [26].

Mental work increases BP. The underlying mechanisms that stimulate the cardiovascular response due to mental work is still not clearly understood; however, a contraction in cardiac parasympathetic tone may be accountable for the hemodynamic changes [24]. Another possibility is an increase [27] or decrease [28] muscle sympathetic nerve stimulation, which exemplifies the actions of the sympathetic nervous system [29] as a result of mental activity.

Since both HR and BP increased during mental activity compared to resting states, a reestablishment of the driving point of baroreflex to a higher BP must have been induced by mental work [30]. Possibly, this could be another mechanism that attempts to clarify the cardiovascular changes.

\section{Effect of mental stress in HRV}

Our study also observed changes in cardiac autonomic function using HRV during mental stress. There was a significant decrease in markers of parasympathetic activity i.e., RMSSD, NN50, and pNN50. The mental stress of mild intensity induces parasympathetic withdrawal [31-33]. Other studies have also shown a decrease in SDNN [1], whereas, in our study, the SDNN was reduced during stress but was not statistically significant.

Another measure of HRV analysis is Power Spectral Density. It yields knowledge about how power is distributed in the form of frequency. It also helps to distinguish between the activity of the sympathetic and parasympathetic nervous systems. Our study found a significant reduction in LF and HF powers. LF power reflects activity of both arms of autonomic nervous system (parasympathetic and sympathetic), while $\mathrm{HF}$ power measures only parasympathetic activity [1]. We found no changes in LF nu and LF/HF ratio, both of which are the markers of sympathetic stimulation. These results additionally indicate that only withdrawal of parasympathetic activity occurred during acute mental stress.

Thus, the findings obtained from HRV in this study undoubtedly points out that a decrease in cardiac parasympathetic tone is responsible for the rise in HR during mental activity. Likewise, another factor could be attenuated baroreflex sensitivity in response to mental work. Nonetheless, further researches are still required to discern the impact of mental work on cardiac autonomic modulation.

\section{Response of the cardiovascular system to recovery from mental stress}

During recovery, the cardiorespiratory variables returned to resting values within five minutes. Additionally, HRV during recovery was also comparable to resting, whereas other studies have found that BP increased with mental activity and remained significantly elevated even during recovery [26]. The degree of the acute changes in BP brought about by acute mental stress may not be a matter to worry about in young, healthy individuals, but such increase in BP produced by mental activity, for a long duration, 
could cause progression to future cardiovascular disease risk [26, 34, 35]. On the other hand, an adjustment in cardiovascular variables might occur when such stress are exposed in a chronic basis. Hence, further researches are required to figure out the influence of mental activity during the recovery phase.

\section{Conclusion}

The acute mental stress of $5 \mathrm{~min}$ in the form of MENSA workout questionnaire (9 sample questions) increased the blood pressure and heart rate in young, healthy male medical students. These cardiovascular changes seem to be brought by parasympathetic withdrawal during mental stress. These males recovered from the mental stress within 5 min.

\section{Limitation and future scope of the study}

The stress level was not accessed using cortisol, which could have provided a better outlook to the study.

\section{Abbreviations}

Blood pressure (BP), B.P. Koirala Institute of Health Sciences (BPKIHS), Diastolic BP (DBP), Electrocardiogram (ECG), Heart rate (HR), HRM (Heart rate monitor), heart rate variability (HRV), high frequency (HF), low frequency (LF), number of RR intervals that differ by $\geq 50 \mathrm{~ms}$ (NN50), normalized units (nu) parasympathetic nervous system (PNS), percentage of NN50 (pNN50), Pulse Rate (PR), Respiratory rate (RR), root mean square of differences of successive RR intervals (RMSSD) sinus node (SA node), sympathetic nervous system (SNS), Systolic BP (SBP), standard deviation of the mean R-R interval (SDRR/ SDNN), total power (TP), very low frequency (VLF)

\section{Acknowledgments}

We thank all the participants for volunteering during the study. Also, sincere appreciation to all the faculty members and staffs of Department of Basic and Clinical Physiology, BPKIHS for their support during the study period.

\section{Authors' contribution}
a. Study planning: KRP, RK, BHP
b. Data collection: KRP, DRP
c. Data analysis/ interpretation: RK, KRP, DRP
d. Manuscript writing: KRP
e. Manuscript revision: KRP, RK, DRP, KA, BHP
f. Final approval: KRP, RK, DRP, KA, BHP
g. agreement to be accountable for all aspects of the work: KRP, RK, DRP, KA, BHP

\section{Funding}

No funding was available for this research study.

\section{Availability of data and materials}

All data underlying the results are available as part of the article, and no additional source data are required separately as additional material for this research.

\section{Competing interests}

None declared.

\section{Publisher's Note}

NHRS remains neutral with regard to jurisdictional claims in published maps and institutional affiliations.

The publisher shall not be legally responsible for any types of loss, actions, claims, proceedings, demand or costs or damages whatsoever or howsoever caused arising directly or indirectly in connection with or arising out of the use of this material.

\section{Author information}

${ }^{1}$ Dr. Karishma Rajbhandari Pandey, Associate Professor, Department of Basic and Clinical Physiology

${ }^{2}$ Dr. Rita Khadka, MSc. PhD, Additional Professor, Department of Basic and Clinical Physiology,

${ }^{3}$ Dr. Dipesh Raj Panday, Assistant Professor, Department of Pharmacology

${ }^{4}$ Dr. Kopila Agrawal, B.D.S, MD, Department of Physiology

${ }^{5}$ Prof. Dr. Bishnu Hari Paudel, Professor, Department of Basic and Clinical Physiology

${ }^{1-3,}{ }^{5}$ B.P. Koirala Institute of Health Sciences (BPKIHS), Dharan, Nepal.

${ }^{4}$ Birat Medical College, Biratnagar, Dharan

\section{References}

1. Kim HG, Cheon EJ, Bai DS, Lee YH, Koo BH. Stress and Heart Rate Variability: A MetaAnalysis and Review of the Literature, Psychiatry Investig. 2018;15(3):235-45 https://doi.org/10.30773/pi.2017.08.17

2. Bramness G, Fixdal TC, Vaglum P. Effect of medical school stress on the mental health of medical students in early and late clinical curriculum. Acta Psychiatr Scand. 1991;84(4):340-5

https://doi.org/10.1111/j.16000447.1991.tb03157.x

3. DJ Crews, DM Landers. A meta-analytic review of aerobic fitness and reactivity to psychosocial stressors. Medicine \& Science in Sports \& Exercise. 1987;19(5, Suppl): 114-120 https://doi.org/10.1249/00005768-198710001$\underline{00004}$

4. Huang CJ, Webb HE, Zourdos MC, Acevedo EO. Cardiovascular reactivity, stress, and physical activity. Front Physiol. 2013;4:314 
JBS 2020;7(1):11-17

https://doi.org/10.3389/fphys.2013.00314

5. Pollard TM, G Ungpakorn, GA Harrison, KR Parkes, TM Pollard. Epinephrine and cortisol responses to work: A test of the models of Frankenhaeuser and Karasek, Ann Behav Med Fall 1996;18(4):229-37 https://doi.org/10.1007/BF02895284

6. Gerra G, Zaimovic A, Mascetti GG, Gardini S, Zambelli U, Timpano M, et al. Neuroendocrine responses to experimentally-induced psychological stress in healthy humans. Psychoneuroendocrinology. 2001; 26(1):91-107. https://doi.org/10.1016/S0306-4530(00)00046-9

7. Almeida MB, Araújo CGS. Effects of aerobic training on heart rate. Rev. Bras. Med. Do Esporte. 9 (2003):113-20.

https://doi.org/10.1590/S151786922003000200006

8. Smeets PAM, Erkner AC. de Graaf, Cephalic phase responses and appetite. Nutr. Rev. 68 (2010) 643-655.

https://doi.org/10.1111/j.17534887.2010.00334.x

9. Kaufman MP, Hayes SG. The exercise pressor reflex., Clin. Auton. Res. 12 (2002):429-39. https://doi.org/10.1007/s10286-002-0059-1

10. Järvinen A, Dering $\mathrm{B}$, Neumann $\mathrm{D}, \mathrm{Ng} \mathrm{R}$, Crivelli D, Grichanik M, et al. Sensitivity of the autonomic nervous system to visual and auditory affect across social and non-social domains in Williams syndrome, Front Psychol. 2012; 3: 343. https://doi.org/10.3389/fpsyg.2012.00343

11. Chida Y, Steptoe A. Greater Cardiovascular Responses to Laboratory Mental Stress Are Associated With Poor Subsequent Cardiovascular Risk Status, Hypertension.2010;55:1026-32.

https://doi.org/10.1161/HYPERTENSIONAHA.1 $\underline{09.146621}$

12. Steptoe A, Kivimaki M. Stress and cardiovascular disease., Nat. Rev. Cardiol.2012;9,360-370. https://doi.org/10.1038/nrcardio.2012.45

13. Berntson GG, Bigger JTJ, Eckberg DL, Grossman P, Kaufmann PG, Malik M, et al. Heart rate variability: origins, methods, and interpretive caveats., Psychophysiology. 34 (1997) 623-648.

https://doi.org/10.1111/j.14698986.1997.tb02140.x

14. Boutcher SH, Stocker D, Cardiovascular response of young and older males to mental challenge. Journals Gerontol. Ser. B Psychol. Sci.
Soc. $\quad$ Sci. $51 \quad$ (1996) 261-267.

https://doi.org/10.1093/geronb/51B.5.P261

15. de Geus EJ, Willemsen $\mathrm{GH}$, Klaver $\mathrm{CH}$, van Doornen LJ., Ambulatory measurement of respiratory sinus arrhythmia and respiration rate, Biol. Psychol. 41 (1995) 205-227. https://doi.org/10.1016/0301-0511(95)05137-6

16. Billman GE, Heart rate variability - a historical perspective. Front. Physiol. $2011 ; 2,86$. https://doi.org/10.3389/fphys.2011.00086

17. Lipsitz LA, Mietus J, Moody GB, Goldberger AL. Spectral characteristics of heart rate variability before and during postural tilt. Relations to aging and risk of syncope. Circulation. 1990;81(6):1803-10 https://doi.org/10.1161/01.CIR.81.6.1803

18. Lipsitz LA, AL Goldberger. Loss of "complexity" and aging. Potential applications of fractals and chaos theory to senescence. JAMA. 1992; 267(13):1806-9.

https://doi.org/10.1001/jama.1992.034801301220 $\underline{36}$

19. Goldberger AL, Amaral LAN, Hausdorff JM, PC Ivanov, Peng CK, Stanley HE. Fractal dynamics in physiology: alterations with disease and aging. Proc. Natl. Acad. Sci. U. S. A. 2002;99 Suppl 1(Suppl 1):2466-72

https://doi.org/10.1073/pnas.012579499

20. Pincus SM, Goldberger AL. Physiological timeseries analysis: what does regularity quantify? Am. J. Physiol. 1994; 266(4 Pt 2):H1643-56. https://doi.org/10.1152/ajpheart.1994.266.4.H164 $\underline{3}$

21. Mensa Workout Questionnaire, (n.d.). Online Workout [Internet]. MENSA. 2020 [cited 10 May 2020]. Available from: http://www.mensa.org/workout/quiz

22. Ross AE, Flaa A, Hoieggen A, Reims H, Eide IK, Kjeldsen SE. Gender specific sympathetic and hemorrheological responses to mental stress in healthy young subjects., Scand. Cardiovasc.2001; 35(5):307-12 https://doi.org/10.1080/140174301317116271

23. Martin EA, Tan SL, MacBride LR, Lavi S, Lerman LO, Lerman A. Sex differences in vascular and endothelial responses to acute mental stress, Clin. Auton. Res.2008; 18 (6):33945. https://doi.org/10.1007/s10286-008-0497-5

24. 24. Pérusse-Lachance E, Tremblay A, Chaput JP, Poirier P, Teasdale N, Drapeau V. Mental Work Stimulates Cardiovascular Responses through a Reduction in Cardiac Parasympathetic 
JBS 2020;7(1):11-17

Modulation in Men and Women, Bioenergetics.2012;2(1):1-6 https://doi.org/10.1249/01.MSS.0000402077.918 $\underline{46 . \mathrm{d} 8}$

25. Durocher JJ, Klein JC, Carter JR. Attenuation of sympathetic baroreflex sensitivity during the onset of acute mental stress in humans. Am J Physiol Hear. Circ Physiol. 2011; 300 (5):H1788-93.

https://doi.org/10.1152/ajpheart.00942.2010

26. Hjortskov N, Rissen D, Blangsted AK, Fallentin $\mathrm{N}$, Lundberg U, Sogaard K. The effect of mental stress on heart rate variability and blood pressure during computer work, Eur J Appl Physiol.2004; 92(1-2):84-9.

https://doi.org/10.1007/s00421-004-1055-Z

27. Carter JR, Ray CA. Sympathetic neural responses to mental stress: responders, nonresponders and sex differences. Am. J. Physiol. - Hear. Circ. Physiol. 296 2009; 296 (3):H847-H853. https://doi.org/10.1152/ajpheart.01234.2008

28. Matsukawa T, Gotoh E, Uneda S, Miyajima E, Shionoiri H, Tochikubo O, Ishii M. Augmented sympathetic nerve activity in response to stressors in young borderline hypertensive men. Acta Physiol. Scand. 1991; 141(2):157-65. https://doi.org/10.1111/j.17481716.1991.tb09064.x

29. Carter JR, Durocher JJ, Kern RP. Neural and cardiovascular responses to emotional stress in humans. Am. J. Physiol. Regul. Integr. Comp. Physiol. 2008; 295(6):R1898-903.

https://doi.org/10.1152/ajpregu.90646.2008

30. 30. Raven PB, Fadel PJ, Ogoh S. Arterial baroreflex resetting during exercise: a current perspective. Exp. Physiol. 2006; 91(1):37-49. https://doi.org/10.1113/expphysiol.2005.032250

31. Taelman J, Vandeput S, Vlemincx E, Spaepen A, Huffel SV. Instantaneous changes in heart rate regulation due to mental load in simulated office work. Eur. J. Appl. Physiol. 2011; 111 (7):1497505.

https://doi.org/10.1007/s00421-010-1776-0

32. Dimitriev D, Saperova E, Sokolova O. Nonlinear parameters of heart rate variability during mental stress test. Physiology 2012 (Edinburgh) (2012) Proc Physiol Soc 27, PC185.

33. Paritala SA. Effects of physical and mental tasks on heart rate variability, Louisiana State University and Agricultural and Mechanical College, 2009.

34. Wright RA, Stewart CC, Barnett BR. Mental fatigue influence on effort-related cardiovascular response: extension across the regulatory (inhibitory)/non-regulatory performance dimension. Int. J. Psychophysiol. 2008; 69 (2):127-33. https://doi.org/10.1016/j.ijpsycho.2008.04.002

35. Williams RB, Lane JD, Kuhn CM, Melosh W, White AD, Schanberg SM. Type A behaviour and elevated physiological and neuroendocrine responses to cognitive tasks, Science.1982;(218):483-5.

https://doi.org/10.1126/science.7123248 